\title{
Uma avaliação dos impactos da Indústria 4.0 sobre o setor aeronáutico
}

\author{
Marcos José Barbieri Ferreira* (D) \\ Celso Pereira Neris Jr** (D)
}

* Universidade Estadual de Campinas (Unicamp), Campinas, SP, Brasil.

E-mail: marcosbf@unicamp.br

** Universidade Estadual Paulista (Unesp), Araraquara, SP, Brasil.

E-mail: cnerisjr@gmail.com

\section{ResUmo}

Este trabalho procura discutir e avaliar os impactos do conjunto de tecnologias associadas à Indústria 4.0 no setor aeronáutico. Foram selecionadas e conceituadas as principais tecnologias com elevado potencial de impacto na indústria aeronáutica, indicando a capacidade transformadora de cada uma delas. A partir disso, estabeleceu-se uma tipologia dos impactos destas tecnologias nos vários segmentos da indústria aeronáutica procurando qualificar as alteraçóes na estrutura de mercado como: (i) insignificantes; (ii) pequenas, quando há empresas entrantes; (iii) intermediárias, quando se estabelece um novo modelo de negócio; e (iv) grandes, quando há a criação de novas categorias de produtos. Ademais, procurou-se mostrar a possibilidade da formação de um novo segmento que estará centrado na oferta de serviços de transporte aéreo urbano de uso compartilhado, com a utilização de veículos de pouso e decolagem vertical, propulsão elétrica e pilotagem autônoma, conformando o papel disruptivo das tecnologias analisadas.

Palavras-CHaVe | Indústria aeronáutica; Mudança tecnológica; Indústria 4.0 


\title{
An assessment of the impacts of Industry 4.0 on aeronautical industry
}

\begin{abstract}
This paper seeks to discuss and evaluate the impacts of the group of innovations brought by industry 4.0 in the aeronautical sector. Were selected and conceptualized the main technologies with high possibility of transforming the aeronautical industry, indicating the transforming capacity of each one. As a result, it was defined a typology of impacts of these technologies in the various segments of the aviation industry looking qualify the changes in market structure: (i) negligible; (ii) small when there are new entrants; (iii) intermediate, when establishing a new business model and; (iv) large, when there is the creation of new product categories. In addition, we try to show the possibility of creating a new segment that will focus on providing urban air transport services for shared use, with the use of landing vehicles and vertical takeoff, electrical propulsion and autonomous driving, shaping the disruptive role of analyzed technologies.
\end{abstract}

KeYwords | Aeronautical industry; Technological change; Industry 4.0

JEL: $\mathrm{LI}_{1} ; \mathrm{O}_{3}$; $\mathrm{O}_{33}$ 


\section{Introdução}

Este trabalho procura discutir o papel das recentes mudanças tecnológicas, em grande parte identificadas com a Indústria 4.0, na estrutura de mercado da indústria aeronáutica. Parte-se aqui do entendimento de que elas são capazes de impactar no modo como as empresas produzem, ao alterar significativamente a eficiência dos seus processos produtivos ou mesmo permitirem novas funçóes; como estão organizadas, pois estabelece a possibilidade de uma produção mais integrada localmente, por exemplo; e no que produzem, uma vez que propicia o surgimento de novos produtos. Pretende-se mostrar que as novas tecnologias, particularmente as vinculadas à Indústria 4.0, estão provocando alteraçôes significativas na estrutura de mercado do setor aeronáutico.

Para isto, inicialmente é feita uma breve análise da literatura com o objetivo de identificar os elementos que afetam uma estrutura de mercado, por meio das mudanças tecnológicas. Procura-se identificar, ao longo da revisão teórica, como a indústria aeronáutica é um exemplo das relaçóes examinadas pela abordagem neoschumpeteriana. Em seguida, na terceira seção, à luz do abrangente estudo denominado "O projeto Indústria 2027: riscos e oportunidades para o Brasil diante de inovaçóes disruptivas" (COUTINHO et al., 2018), foram selecionadas algumas das principais tecnologias que possuem grande possibilidade de impactos no setor aeronáutico nos próximos dez anos. A seção 4 apresenta os segmentos que compóem a indústria aeronáutica evidenciando, em cada um deles: (a) estrutura de mercado atual; (b) quais tecnologias e como elas os impactam atualmente; e (c) as mudanças que podem ser observadas em (a) decorrentes de (b). Esta forma de apresentação contém o desafio de identificar as alteraçôes na indústria aeronáutica estando elas ainda em curso, de modo que será possível também apontar, em alguns momentos, as expectativas de como este setor poderá se conformar ao longo dos próximos dez anos. Na seção 5 são sistematizados os resultados e a discussão dos impactos das novas tecnologias sobre a estrutura de mercado e estabelecida uma tipologia das mudanças discutidas nos segmentos. Por fim, a seção 6 é dedicada às considerações finais.

\section{Mudança técnica, estrutura de mercado e revoluções tecnológicas}

A mudança técnica está muito bem documentada e analisada por autores vinculados à economia evolucionária ou neoschumpeteriana. Inspirados nos trabalhos de 
Schumpeter $(1934,1942)$, os autores associados a esta abordagem tratam a inovação tecnológica como um elemento de mudança potencial da realidade econômica, uma vez que ela carrega consigo a possibilidade de alterar as estruturas de mercado subjacentes - que compreendem as posiçôes das firmas, no âmbito dos seus setores de atuação, em termos de market share, que, em última instância, está relacionado à mudança ou não daquilo que elas fazem e/ou podem fazer.

Para se analisar o papel das mudanças associadas às tecnologias da chamada Indústria 4.0 e seus impactos na indústria aeronáutica, alguns elementos da teoria neoschumpeteriana tratados aqui permitirão balizar a discussão. Em primeiro lugar, destaca-se o conceito de "destruição criativa" de Schumpeter (1942, p. 83). O termo trata do estabelecimento de novos produtos, novos processos, novas formas de organização e serviços que implicam a emergência de novos parâmetros de concorrência, novas estruturas de mercado ou, no mínimo, de uma nova rotina das firmas. É este impulso incessante das firmas por inovaçóes, visando a construçấo de vantagens competitivas em relação aos seus concorrentes, o responsável pelo caráter de evolução permanente das economias. Necessário distinguir, de antemão, o caráter "endógeno" e "exógeno" do progresso tecnológico (DOSI, 1982, p. 25). As mudanças exógenas estão relacionadas à emergência de novos "paradigmas" tecnológicos, enquanto as endógenas relacionam-se aos caminhos da resolução de problemas tomados pelas firmas, isto é, são as "trajetórias" definidas por esses paradigmas.

Paradigma tecnológico é definido, segundo Dosi (1988), como uma convenção técnica ou científica a respeito das possibilidades de soluçáo de problemas encontrados no processo de criação e produção de artefatos. Portanto, ele tem implícita uma série de direçóes específicas que podem ser tomadas pela firma. Tais trajetórias podem ser descritas como um trade-off multidimensional entre as variáveis tecnológicas que o paradigma define como relevante, de forma que o progresso ao longo de uma trajetória possa ser definido como a melhoria destes trade-offs. Isto implica que as firmas "atuam dentro de um espectro de possibilidades" (FREEMAN; SOETE, 1997, p. 456). Estas possibilidades são oriundas da dinâmica tecnológica na qual as firmas estão inseridas. Mas, nem todas as firmas são capazes de perceber e, com isso, aproveitarem-se, em termos de vantagem concorrencial, dos processos de mudança. É por esta razáo que Nelson e Winter (1977) afirmam que as firmas diferem na medida em que exploram tais trajetórias e essas diferenças no aproveitamento de oportunidades influenciam, em última instância, a ascensão e queda de diferentes tecnologias e setores.

Dois motivos, em um primeiro momento, podem ser elencados sobre a probabilidade de as firmas aproveitarem ou não essas oportunidades. Em primeiro 
lugar, a base produtiva e tecnológica por elas desenvolvida internamente ao longo do tempo (PENROSE, 1959, p. 176). Existe um potencial a ser exercido, a partir dos recursos e conhecimentos acumulados, de utilizaçóes distintas das rotineiras, que depende da busca das firmas (NELSON; WINTER, 1982). Evidente, que isto não se dá de maneira homogênea entre os diversos setores da indústria, o que é mais um elemento de risco a se considerar na decisão de inovar de determinadas empresas. A mudança de trajetória, uma vez assumida, não se altera facilmente, particularmente quando existem elevados custos irrecuperáveis (sunk costs). Cabe ainda ressaltar que a base tecnológica de uma firma não é desenvolvida apenas internamente. A interação com centros de pesquisa, universidades e outros atores que constituem os sistemas setoriais de inovação (MALERBA, 2002) e os sistemas nacionais de inovação (LUNDVALL, 2007) são fundamentais para a expansão e atualização desta base, a partir do (entre outras coisas) processo de interação entre aquilo que é considerado ciência básica e tecnologia aplicada. No caso da indústria aeronáutica, a organização e o funcionamento de empresas aeronáuticas ocorrem através de sistemas locais de inovação, a exemplo de Toulouse na França e Seattle nos EUA.

O segundo motivo está relacionado com as expectativas e incertezas decorrentes da adoção de uma determinada direção tecnológica. Nesse sentido, a mudança técnica empreendida por uma firma pode ser considerada uma aposta que deve ser feita mediante a (tentativa de) diminuição dos riscos potenciais, apenas parcialmente antecipados. Este tema é tratado por Rosenberg (2006) em seu capítulo sobre as expectativas tecnológicas. $\mathrm{O}$ autor traz uma série de casos a respeito do ritmo com que tecnologias existentes são aprimoradas e novas tecnologias são adotadas. Segundo ele, "a escolha do momento e a natureza da decisão da adoção [das inovaçóes tecnológicas], por parte das firmas de negócios individuais, é uma questão-chave”. (ROSENBERG, 2006, p. 164). Constata-se que esta "incerteza tecnológica" é um elemento que estabelece uma diferença ainda maior no comportamento entre as firmas, pois estas são diferentes nos seus diversos "graus de aversão ao risco". Na indústria aeronáutica, essa incerteza é agravada, ainda mais, pelos elevados custos de introduçấo das inovaçóes radicais. O desenvolvimento de uma nova geração de aeronaves tem atingido valores cada vez mais elevados, de forma que uma inovação malsucedida passa a comprometer a sobrevivência da própria empresa (FERREIRA, 2009).

Ademais, o ambiente de incerteza é claramente maior quando se deflagram novas possibilidades tecnológicas, em geral, associadas às grandes revoluçóes tecno-econômicas (PEREZ, 2010). Existe, no entanto, um processo de estabilização entendido como uma direçáo parcialmente definida da trajetória tecnológica - que 
decorre do processo da coevolução da tecnologia, estrutura industrial e instituiçôes (NELSON, 1995). Em primeiro lugar, destaca-se a coevolução entre tecnologia e estrutura industrial. Nelson (1995) apresenta o argumento de Abertnathy e Utterback (1978), neste sentido. Segundo os autores, quando novas tecnologias surgem, há considerável incerteza acerca da variedade de possibilidades decorrentes, pois diferentes combinaçôes serão tentadas em diferentes lugares até que, após um período de experimentação, um denominado projeto dominante será identificado e reconhecido. De acordo com Utterback (1996, p. 93):

O caso do aviāo DC-3 é um exemplo de como o consenso pode ser obtido em um produto. $O D C-3$ (...) é o ápice de inovaçóes anteriores e estabeleceu o padrão para aeronaves comerciais por duas décadas. Ele não foi o maior, nem o mais rápido, nem o aviāo com maior raio de ação a voar quando foi lançado, mas era simplesmente o único avião econômico, grande e rápido, capaz de voar longas distâncias. O DC-3 atendeu a necessidades de mercado de maneira tão eficaz que, na verdade, ele forneceu os conceitos básicos para o projeto de aeronaves comerciais desde o instante de sua criação, na metade da década de 30, até o aparecimento dos jatos comerciais no final dos anos 50 .

De acordo com Nelson (1995, p. 51-55), se as tecnologias possuem um alto grau de cumulatividade, é natural esperar uma vantagem inicial daqueles que "saíram na frente" em seus processos inovativos, na definição do projeto dominante. Entretanto, de acordo com Mowery e Rosenberg (2005, p. 80) existem os riscos de ser o "primeiro do mercado" na aplicação de uma nova tecnologia disruptiva. Por exemplo, a introduçáo do jato Comet da DeHavilland em 1952 acabou sendo um desastre, pois a falha em prever a fadiga dos metais resultou em uma série de acidentes e no fracasso comercial da aeronave. O Boeing 707, que surgiu em seguida, corrigiu esta falha e não apenas se tornou um grande sucesso de mercado, como definiu os novos parâmetros para os futuros aviōes comerciais a jato.

Nelson (1995, p. 55-57) enfatiza ainda a importância do conjunto do ambiente institucional para o desenvolvimento e consolidação de uma determinada mudança tecnológica. De acordo com o autor é necessária uma evolução conjunta não só no âmbito das firmas, mas também de associaçóes técnicas, universidades, legislação, agências governamentais que devem adaptar-se a tais mudanças e, de alguma forma, de maneira recursiva, também influenciar a direção destas mudanças. Por esta razão, pode-se dizer que o processo inovativo é altamente complexo, envolve uma diver- 
sidade de atores e se move em um ambiente de incerteza. Isso tem como corolário uma série de modelos que tentam captar, ao menos logicamente, como a inovação se dá (ver, por exemplo, o modelo de KLINE; ROSENBERG, 1986, utilizado pelo Manual de Oslo, 2005, da Organização para a Cooperação e Desenvolvimento Econômico - OCDE).

Para avançar na análise das grandes mudanças que dáo origem a todo esse movimento das firmas, alguns comentários são necessários sobre o âmbito macro, cujas raízes estão profundamente nos microfundamentos da mudança tecnológica já aqui mencionados. Carlota Perez (2010) discute isto a partir da ideia de revoluçóes tecnológicas. Para ela, ao longo do tempo, uma tecnologia individual inicia uma revolução - uma espécie de big bang - que, em seguida, desencadeia uma série de melhoramentos exploratórios até que se chegue a uma trajetória definida, na qual existirá um projeto dominante. Após essa fase, até o processo de maturidade tecnológica (último estágio), as direçôes da trajetória da tecnologia inicial vão ficando mais claramente definidas, de modo que os melhoramentos se darão de maneira mais aceleradas e uma série de modelos seráo estabelecidos até, enfim, serem exauridas todas as possibilidades de melhoria. Quando isto acontece, a tecnologia pode ser considerada madura.

Diante disso, a revolução tecnológica pode ser definida como aquela na qual há, concomitantemente, um conjunto de avanços disruptivos inter-relacionados, que formam uma constelação de tecnologias interdependentes, isto é, "um cluster de clusters" (PEREZ, 2010 2 p. 189). Por exemplo, o desenvolvimento computacional nos anos 1970, cujo big bang foi possibilitado pelo advento dos microprocessadores, foi seguido por uma série de produtos e processos que provocaram feedback loops tanto nas tecnologias, quanto nos mercados, resultando na revolução da tecnologia de informação dos anos 1980 (COUTINHO, 1992). Para Perez (2010), o que distingue uma revolução tecnológica de uma coleção aleatória de sistemas tecnológicos são duas características: (i) a forte interconectividade e interdependência dos sistemas participantes em suas tecnologias e mercados e (ii) a capacidade de transformar profundamente o restante da economia e, eventualmente, a própria sociedade.

A partir das consideraçóes aqui desenvolvidas, observa-se atualmente uma mudança tecnológica em curso, centrada na evolução tecnológica de sistemas integrados para os sistemas ciber-físicos, simplificadamente denominada como Indústria 4.0 (ERBOZ, 2017). Este amplo conjunto de inovaçôes vêm remodelando a produção, a distribuiçáo e o consumo, possibilitando o surgimento de novos modelos de negócios e, inclusive, a criação de novos setores econômicos (SCHWAB, 2016). Neste 
contexto, segue uma discussão sobre as principais tecnologias - particularmente as trazidas pela Indústria 4.0 - julgadas, na presente análise, as mais relevantes para o setor aeronáutico e, em seguida, uma avaliação dos seus impactos sobre a estrutura produtiva desse setor industrial.

\section{Principais tecnologias da Indústria 4.0 relacionadas ao setor aeronáutico}

Esta seção busca identificar e analisar as principais inovações tecnológicas que vêm impactando a competitividade da indústria aeronáutica mundial hodiernamente (MCKINSEY, 2016). Uma parte significativa das inovaçóes está diretamente relacionada com as tecnologias da Indústria 4.0 e estáo reunidas em quatro clusters que operam de maneira complementar e integrada, sendo eles: inteligência artificial, tecnologias de redes, internet das coisas, além das inovaçóes relacionadas diretamente com a atividade fabril reunidas no cluster denominado produção inteligente e conectada. Na sequência, também são apresentados dois clusters de inovações que estão indiretamente relacionados com a Indústria 4.0, um específico para as inovaçóes na área de materiais e o último, que engloba as tecnologias relacionadas com o armazenamento de energia. Desta maneira, as tecnologias-chave podem ser agrupadas em seis clusters - definidos de acordo com as especialidades dos conhecimentos envolvidos - com o objetivo de reconhecer as principais tendências para esta indústria (KLOTZEL, 2015).

\subsection{Inteligência Artificial (IA)}

A inteligência artificial vem apresentando uma excepcional expansão nos últimos anos em decorrência de dois fatores. Primeiro, o grande volume de dados que vem sendo gerado e disponibilizado por conta do avanço da digitalização. Segundo, a elevada capacidade e velocidade de armazenamento, processamento e análise desses dados, que é resultado tanto de hardwares mais potentes como de softwares mais avançados. Entre os instrumentos mais difundidos da IA tem-se o big data e o machine learning (PRADO, 2017). Na indústria aeroespacial destaca-se a utilização da IA para: (i) monitorar e aperfeiçoar o desempenho das aeronaves, particularmente no que se refere à sua manutenção; (ii) utilizar os dados sobre voos, passageiros e cargas em serviços oferecidos aos clientes de acordo com suas necessidades (CRABBE, 2013). Destaca-se cada vez mais a inter-relação dos serviços com atividades manufa- 
tureiras e seu aumento em termos de valor adicionado, a denominada "servitização" (MILES, 2006); (iii) melhorar a interface homem-máquina, com destaque para o uso dos comandos de voz; (iv) gerar e identificar imagens, por exemplo, a realidade virtual dos simuladores de voo cada vez mais confiáveis, eficientes e baratos; (v) implementar a pilotagem (parcialmente) autônoma; e (vi) otimizar as atividades produtivas e administrativas.

\subsection{Novas Tecnologias de Rede}

As tecnologias de redes têm um papel-chave na indústria aeronáutica, pois permitem a integração em três diferentes níveis. No âmbito do produto, as avançadas redes de fibra ópticas possibilitam a integração dos sistemas de controle da aeronave, denominadas fly-by-light. No nível do processo produtivo das aeronaves, as novas tecnologias de rede possibilitam a integração desde o ambiente da fábrica até as cadeias globais de suprimentos. Por fim, no nível dos "sistemas de sistemas", destaca-se a integração do ambiente de voo, através dos novos sistemas de controle de tráfego aéreo ou, na área militar, dos sistemas de guerra centrada em redes (network-centric warfare). Ambos baseados na tecnologia de comunicação por dados em tempo real (datalink) (WILSON, 2007). Dado que essas tecnologias de rede passam a ocupar uma posiçẫo imprescindível e cada vez mais importante na indústria aeronáutica, o desempenho e a segurança das redes (cyber security) são os dois requisitos chaves na trajetória de evolução dessa tecnologia nesta indústria (LORAL, 2017).

\subsection{Internet das Coisas (IoT)}

A internet das coisas (Internet of Things - IoT) possibilita captar as informaçóes através de sensores e retornar as açōes através de atuadores. Desta maneira, está necessariamente integrada com as tecnologias de IA, que possibilita o processamento "inteligente" das informaçôes coletadas e das redes, que permitem a transmissão destas informaçóes. Por exemplo, uma "aeronave incorpora capacidade computacional embarcada e os dados produzidos pelos sensores são analisados em tempo real por meio de inteligência artificial distribuída, de modo que os diagnósticos possam ser feitos ainda durante o voo" (BORDEAUX-REGO, 2017, p. 11). O elevado volume de informaçóes captadas pelos modernos sensores, processadas e transmitidas aos atuadores, possibilita melhor desempenho e maior segurança das aeronaves, além de reduzir os custos operacionais, bem como otimizar as manutençôes, informando 
qual o tipo de intervenção necessária e quando esta deve ser realizada (manutençôes preditivas). As inovaçôes mais disruptivas da IoT estâo atualmente direcionadas às operaçóes com drones, possibilitando uma crescente automatização nas operaçôes desses veículos.

\subsection{Produção Inteligente e Conectada (PIC)}

A produção inteligente e conectada abrange um conjunto de tecnologias inovadoras e inter-relacionadas que está sendo incorporado ao processo produtivo dos setores industriais mais avançados (NAVEIRO, 2017). Estas tecnologias estão intrinsecamente associadas às tecnologias de redes, IA e IoT. Na indústria aeronáutica, a PIC está avançando em quatro tecnologias centrais: (i) robótica - utilizada em atividades repetitivas e que necessitam de elevada precisão, como a furação e colocação de rebites nas aeroestruturas. Desta maneira, a automação está avançando nos segmentos que apresentam maiores escalas, produtos padronizados e elevada carga de trabalho humana, como a montagem de grandes avióes comerciais (WEBER, 2015); (ii) manufatura aditiva - também conhecida como impressão $3 \mathrm{D}$, que está restrita aos componentes de elevada complexidade de projeto e alto valor agregado; (iii) novos processos produtivos - com destaque para as tecnologias que permitem a junção de partes metálicas, sem a necessidade de rebites ou soldagem; e (iv) virtualização da produção - basicamente a simulação de produtos (protótipos) e processos produtivos com elevado realismo e confiabilidade (FERREIRA, 2018).

\subsection{Materiais Avançados (MA)}

A tecnologia de materiais apresenta uma importância central para a indústria aeronáutica em decorrência do baixo peso, elevada resistência e imprescindível segurança que as aeronaves precisam demonstrar (NAYAK, 2014). As principais inovaçôes introduzidas nas tecnologias de materiais são: (i) desenvolvimento das ligas de alta entropia (HEA) que combinam múltiplos elementos; (ii) avanço das ligas leves de metais reforçadas com nanotubos de carbono; (iii) desenvolvimento de compósitos nanoestruturados que combinam a tecnologia dos compósitos convencionais com os nanotubos de carbono; (iv) avanços tecnológicos em metais, polímeros e cerâmicas decorrentes da introdução da tecnologia de manufatura aditiva; e (v) crescente importância das "terras raras", particularmente como insumo na produção de imãs de elevada capacidade, utilizados em motores elétricos e baterias de baixo peso e alto 
desempenho (CARVALHO, 2017). Nos projetos das aeronaves tecnologicamente mais sofisticadas identifica-se que os materiais avançados são utilizados de maneira combinada, buscando-se aproveitar ao máximo as características técnicas de cada um deles.

\subsection{Armazenamento de Energia (AE)}

O principal impacto do cluster de tecnologias de armazenamento de energia voltadas para o setor aeronáutico é o de possibilitar o desenvolvimento de aeronaves de propulsão elétrica e, assim, atender duas importantes demandas. De um lado, a maior eficiência energética, resultando em menores custos operacionais. De outro lado, contribuir para redução das emissões dos gases de efeito estufa. Atualmente, os motores elétricos abastecidos por baterias recarregáveis estão praticamente restritos aos veículos aéreos não tripulados de pequenas dimensôes e a alguns modelos experimentais de avióes leves (TORRESI, 2017).

\section{Impactos das tecnologias da Indústria 4.0 na estrutura de mercado do setor aeronáutico}

A indústria aeronáutica é uma das mais avançadas do mundo em termos de incorporação de novas tecnologias. No entanto, a introdução dessas inovaçóes entre os diferentes segmentos que compóem esta indústria é bastante heterogênea. Por exemplo, enquanto os avióes de caça estâo na fronteira tecnológica incorporando muitas tecnologias disruptivas ainda náo testadas, os aviôes leves utilizados para treinamento e recreação operam com tecnologia já consolidada, utilizando poucas inovaçôes. Seguindo o critério que classifica as aeronaves de acordo com as tecnologias constitutivas e as categorias de uso, neste artigo o setor aeronáutico está dividido em nove diferentes segmentos, como é apresentado no Quadro 1.

\section{QUADRO 1}

Indústria aeronáutica: Classificação em segmentos

\begin{tabular}{|c|c|c|c|c|c|c|c|c|}
\hline \multicolumn{9}{|c|}{ Segmentos } \\
\hline \multicolumn{3}{|c|}{ Militar } & \multicolumn{2}{|c|}{ Comercial } & \multicolumn{2}{|c|}{ Aviaçáo geral } & \multirow{2}{*}{$\begin{array}{c}\text { Asas } \\
\text { rotativas }\end{array}$} & \multirow{2}{*}{$\begin{array}{c}\text { Veículo aéreo } \\
\text { náo tripulado } \\
\text { (VANT) }\end{array}$} \\
\hline Combate & $\begin{array}{l}\text { Treina- } \\
\text { mento }\end{array}$ & $\begin{array}{l}\text { Trans- } \\
\text { porte }\end{array}$ & Jatos & $\begin{array}{l}\text { Turbo- } \\
\text { élices }\end{array}$ & $\begin{array}{c}\text { Jatos } \\
\text { executivos }\end{array}$ & Leves & & \\
\hline
\end{tabular}

Fonte: Elaboraçáo própria. 
Estes nove segmentos que compóem a indústria aeronáutica estão agrupados de acordo com a dimensão do impacto das novas tecnologias da Indústria 4.0 sobre a estrutura de mercado, tendo como perspectiva um prazo de dez anos. Para isto, estabeleceu-se, à luz da discussão teórica, quatro categorias, divididas de acordo com o impacto das novas tecnologias: (a) estruturas de mercado sem alteraçóes significativas; (b) estruturas de mercado com pequenas alteraçôes em decorrência de novos entrantes; (c) alteraçōes intermediárias na estrutura de mercado devido à criaçấo de novos modelos de negócios e, consequentemente, novos entrantes; e (d) grandes alteraçóes na estrutura de mercado resultantes do desenvolvimento de novas categorias de produtos, novos modelos de negócios e novos entrantes. Por fim, cabe ressaltar que o impacto das inovaçóes disruptivas provavelmente resultará na criação de um novo e dinâmico segmento da indústria aeronáutica, no caso o segmento de veículos aéreos urbanos autônomos.

\subsection{Estruturas de mercado sem alterações significativas}

A estrutura de mercado do segmento de asas rotativas é caracterizada como um oligopólio concentrado em nível mundial. Em 2015, mais de 90\% da produção mundial de helicópteros estava restrita a cinco grandes empresas, sendo duas estadunidenses, duas europeias e uma russa (AWIN, 2018). A participação no mercado mundial das empresas de outros países de fora da tríade EUA-Europa-Rússia tem sido muito marginal e, mesmo no caso da China, seus principais projetos estáo direta ou indiretamente vinculados a alguma das grandes fabricantes de helicópteros, na forma de produçóes sob licença e acordos de desenvolvimento conjunto (LEBOULANGER, 2013). Entre os principais avanços tecnológicos destaca-se a utilização de compósitos, que já são empregados, inclusive em componentes críticos, como as pás de sustentação, e devem continuar a ser incorporados de maneira crescente nas cabines. Algumas inovaçôes baseadas nas TICs devem ser incorporadas, de maneira incremental e progressiva ao longo dos próximos dez anos, particularmente as tecnologias de IA, que devem contribuir na interface homem-máquina das aeronaves de asas rotativas. De acordo com Ferreira (2018), a maioria das inovaçóes previstas para década de 2020 no segmento de helicópteros deve apresentar caráter incremental. Os principais esforços inovativos do segmento estão relacionados ao programa Future Vertical Lift (FVL) do Exército dos EUA. Os protótipos estão sendo desenvolvidos pelas empresas líderes (Lockheed Martin e Textron) e somente devem estar operacionais na década de 2030 (JUDSON, 2020). Como resultado, a 
possibilidade de mudanças na estrutura de mercado e de contestação das empresas líderes nos próximos dez anos são praticamente inexistentes.

No segmento dos avióes de combate, atualmente apenas três modelos de avióes de caça de quinta geraçấo estão operacionais, dois desenvolvidos nos EUA pela Lockheed Martin, e um na China pela AVIC. Além desses, em 2020 deve entrar em operação o avião russo Sukhoi Su-57, da United Aircraft Corp. (UAC). Com relação às empresas europeias, em 2017 e 2019 foram apresentados dois programas de caças de quinta geração, respectivamente, o Future Combat Air System (Dassault Aviation e Airbus) e o Tempest (BAE Systems e Leonardo), que deverão entrar em operaçáo apenas na década de 2030 (ALLISON, 2019). Desta maneira, não se deve observar, na década de 2020, mudanças disruptivas decorrentes do lançamento de uma sexta geração de aviōes de caça. A maioria dos avanços tecnológicos no segmento de aviôes de caça deverá ser incremental. No entanto, as inovaçóes mais significativas devem se concentrar na IA, particularmente no que se refere à interface homem-máquina, com a adoção de tecnologias que possibilitem uma completa consciência situacional, maior segurança e redução na carga de trabalho. Juntamente com a IA, a crescente adoção de sensores (IoT) também será essencial para avaliação contínua do desempenho e manutenção das aeronaves. As novas tecnologias de rede devem ser gradualmente incorporadas nos modernos avióes de combate, aprimorando a realização de operaçôes conjuntas e coordenadas em ambientes de rede, denominadas network-centric operations (WILSON, 2007). Com relação aos materiais avançados, os novos modelos devem introduzi-los de maneira progressiva e de forma combinada, como nos atuais aviôes de caça de quinta geração, além disso, o uso da manufatura aditiva deve se intensificar. A estrutura de mercado desse segmento deverá apresentar apenas uma gradual mudança de posição entre as empresas líderes ao longo dos próximos dez anos. As empresas estadunidenses continuarão na liderança comercial e tecnológica, mas agora seguidas pela AVIC chinesa, enquanto as empresas europeias deverão perder participação por conta do relativo atraso tecnológico frente às concorrentes.

\subsection{Estruturas de mercado com alterações pequenas: novos entrantes}

O segmento de grandes jatos comerciais (acima de 150 assentos) estava dividido praticamente ao meio, entre a europeia Airbus e a estadunidense Boeing, constituindo um clássico duopólio. Nos últimos anos, estas duas empresas também buscaram dominar a categoria inferior, de jatos comerciais entre 70 e 150 assentos. 
Em 2020, a Airbus completou a incorporação da moderna família de jatos comerciais CSeries da empresa canadense Bombardier (GARCIA, 2020). Contudo, a Boeing não conseguiu completar a aquisição dos negócios de aviação comercial da empresa brasileira Embraer, devido ao agravamento dos seus próprios problemas técnicos e financeiros (JOSEPHS, 2020; DRUMOND, 2020). Como resultado, a Airbus abriu uma vantagem sobre sua concorrente estadunidense, enquanto a Embraer se manteve na aviação comercial. Buscando manter a liderança tecnológica, os governos dos EUA e da Europa lançaram, recentemente, seus respectivos programas demonstradores de tecnologia, Green Aviation e Clean Sky. A partir destes dois programas, é possível identificar as futuras trajetórias tecnológicas do segmento comercial da indústria aeronáutica, que devem ser incorporados de maneira progressiva em versôes mais avançadas dos modelos existentes ao longo da década de 2020 (KLOTZEL, 2015), como segue: (a) as novas aeronaves comerciais deveráo ser produzidas através da combinação de diferentes materiais, particularmente as novas ligas metálicas e os compósitos nanoestruturados, enquanto os componentes de elevada complexidade deverão ser confeccionados através da manufatura aditiva; (b) as novas tecnologias digitais (IA e IoT) deverão possibilitar um monitoramento detalhado do desempenho das aeronaves. Além disso, as fabricantes de aeronaves devem adotar uma estratégia de servitização e oferecer pacotes combinados de produtos e serviços que atendam as necessidades dos clientes, particularmente aqueles relacionados com a operacionalidade das aeronaves (manutenção, passageiros e voos); e (c) o processo produtivo desse segmento deve ser o mais impactado, no âmbito da indústria aeronáutica, pelas novas tecnologias, dado que as grandes escalas produtivas viabilizam a introdução de sistemas automatizados. Cabe esclarecer, no entanto, que este amplo e integrado conjunto de tecnologias somente deverá resultar em um "novo projeto dominante" da aviação comercial a partir de 2035. Na década de 2020, as principais mudanças estão relacionadas com a contestação do atual duopólio a partir da entrada de novos concorrentes (MANTEGHI et al., 2018). A China está entrando neste mercado com um novo aviáo que incorpora diversos avanços incrementais. $\mathrm{O}$ modelo C919 de corredor único realizou seu primeiro voo em 2017 e deverá entrar em operação em 2021 (QUI, 2020). Outro avião comercial de corredor único que deve entrar em operação no mesmo período é o avião russo Irkut MC-21, da UAC (MEIER, 2020). Além disso, ambas as empresas se uniram num consórcio, denominado China-Russia Commercial Aircraft International Corporation (CRAIC), para desenvolver o avião de fuselagem larga CR929, que deverá entrar em operação até 2028 (GOH, 2017). Destaca-se ainda a japonesa Mitsubishi, que adquiriu em 
2020 a antiga linha de avióes regionais CRJ da Bombardier, visando incorporar competências no seu moroso programa SpaceJet, que deverá entrar em operaçáo em 2022 (HEMMERDINGER, 2020; GATES, 2020). Por fim, cabe mencionar que a pandemia do Covid-19 vem impactando de forma drástica a demanda deste segmento em razão da significativa redução do tráfego aéreo e a consequente postergação e cancelamento das encomendas de novas aeronaves (KPMG, 2020).

A estrutura de mercado do segmento de grandes avióes turboélices de uso comercial é composta pela empresa europeia ATR e pela canadense Viking Air, que atuam praticamente em condiçóes de duopólio, mas com modelos tecnologicamente defasados (AWIN, 2018). Neste contexto, destaca-se a entrada da empresa chinesa AVIC, com o modelo Xian MA700, que deve ser colocado no mercado em 2022. Também existe a expectativa de que outras empresas aeronáuticas entrem neste segmento (HAYNES, 2017). O desinteresse dos principais players em introduzir aeronaves mais inovadoras abre a possibilidade para a entrada de novas empresas. Neste segmento, as futuras aeronaves devem incorporar muitas das tecnologias utilizadas previamente pelos grandes jatos comerciais. Uma parcela significativa das inovações está relacionada com os materiais avançados, dado que as aeronaves comerciais turboélice atuais ainda são produzidas, quase exclusivamente, com ligas de alumínio. As tecnologias relacionadas com IA e IoT também devem ser incorporadas de maneira gradual, objetivando um melhor monitoramento e desempenho das aeronaves. Também devem ser introduzidas inovaçôes incrementais no processo produtivo, visando à crescente automatização das unidades fabris. Com relação ao sistema de propulsão, há uma grande probabilidade de incorporação de motores híbridos turboelétricos, mas estas inovadoras aeronaves devem se tornar operacionais num prazo superior a dez anos. Observa-se, por fim, o grande impacto da pandemia do Covid-19, mas em proporçóes menores que no segmento anterior, dado que as rotas de menor densidade e distância estão sendo menos afetadas (ICAO, 2020).

A produção de aeronaves de transporte militar de médio e grande porte esteve concentrada nos EUA e na Rússia, com uma participação secundária das empresas europeias, japonesas e chinesas. Neste contexto, o impacto das tecnologias derivadas das TICs deve ser incremental e se concentrar na melhoria da navegação e nos aviônicos. Os materiais avançados vêm sendo incorporados de forma progressiva, mas não devem substituir as grandes aeroestruturas. A propulsão elétrica não deve ser introduzida nos próximos projetos de avióes de transporte militar de médio e grande porte dada a necessidade de robustez das aeronaves (FERREIRA, 2018). As maiores possibilidades de mudanças na estrutura de mercado para os próximos dez 
anos estão centradas na entrada de novas empresas, com destaque para a Embraer com o inovador modelo KC-390, que entrou em operação em 2019.

O segmento dos avióes leves de pequeno porte é o que apresenta a estrutura de mercado mais pulverizada da indústria aeronáutica. A baixa sofisticação tecnológica, a pequena importância estratégica e o reduzido volume de capital requerido resultaram em novos empreendimentos e diversas operaçôes de fusôes e aquisiçôes, muitas delas comandadas por empresas de países emergentes. $\mathrm{O}$ principal impacto tecnológico se refere à crescente capacidade de armazenamento de energia das novas baterias, possibilitando motores elétricos em modelos de aeronaves já existentes. Como resultado, observa-se atualmente a parceria de grandes empresas aeronáuticas com fabricantes de motores elétricos, como as parcerias Airbus-RollsRoyce-Siemens e Embraer-Weg, além de start-ups como VoltAero, MagniX e Ampaire, que vêm utilizando este segmento para testar suas inovaçóes, abrindo espaço para que novas empresas também entrem neste segmento ao longo dos próximos anos (THOMSON, 2020). As aeronaves desse segmento também devem continuar a incorporar, de maneira crescente, os materiais avançados, além de algumas inovaçóes incrementais relacionadas com as TICs, como os óculos de realidade aumentada para pilotagem das aeronaves (UBIRATAN, 2014).

\subsection{Estruturas de mercado com alterações intermediárias: novos modelos de negócios e novos entrantes}

O segmento de jatos executivos apresenta uma estrutura de mercado bastante concentrada, dividido entre cinco grandes empresas: a francesa Dassault, a canadense Bombardier, as estadunidenses Gulfstream Aerospace e Cessna e a brasileira Embraer. Constata-se ainda que as inovaçóes em materiais permitiram que a empresa japonesa Honda conquistasse uma significativa parcela deste mercado com o inovador modelo HondaJet, lançado em 2015 (RIBEIRO, 2017). No entanto, as maiores mudanças estão relacionadas às inovaçóes em IA e IoT, com destaque para a crescente integração de sensores que permitam monitorar o desempenho das aeronaves e, consequentemente, a realização das manutenções preditivas. A elevada capacidade de armazenamento e processamento inteligente das informaçóes também está permitindo a constituição de sistemas de gerenciamento de grandes frotas de aeronaves executivas, possibilitando a otimização das operaçôes. Em paralelo, as inovaçóes propiciadas pelas TICs permitirão ampliar esse mercado com a difusão de aplicativos que possibilitem conectar as demandas dos clientes com as ofertas 
de aeronaves. $\mathrm{O}$ resultado deverá ser uma gradual mudança no modelo de negócio com o avanço das empresas de aplicativos na prestaçáo dos serviços de transporte em jatos executivos, de forma customizada e personalizada (BAINES et al., 2017).

A estrutura de mercado do segmento de avióes de treinamento avançado de alto desempenho, denominados Lead-In Fighter Trainer (LIFT) está concentrada em alianças estratégicas constituídas entre as grandes e médias empresas aeronáuticas para o desenvolvimento de projetos específicos (GINADER, 2013). Destaque para as alianças entre: Korea Aerospace Industries (KAI) e Lockheed Martin; Boeing e Saab; Aermacchi e Yakovlev (grupo UAC), além da chinesa AVIC que opera sozinha. Neste segmento os impactos mais disruptivos estão concentrados na IA, com o desenvolvimento de sistemas de treinamento virtual cada vez mais realistas, confiáveis, eficientes e baratos. Como resultado, os simuladores de voo vêm apresentando uma grande difusão e devem ocupar uma parcela cada vez maior no treinamento dos pilotos. A crescente sofisticaçấo tecnológica faz com que seja cada vez mais conveniente a compatibilidade entre as diferentes etapas de treinamento. Em razão disso, uma mudança no modelo de negócio é eminente, e somente as empresas, ou consórcios de empresas, que oferecerem soluçóes completas e integradas (avióes de treinamento avançado, primário e simuladores) deverão manter uma parcela significativa deste mercado (LEBOULANGER; KIMLA, 2013). Existe, ainda, a probabilidade que essas empresas assumam as atividades de treinamento aeronáutico militar de forma direta ou por meio de parcerias público-privadas (PPP), vendendo serviços de formação de pilotos para uma determinada força aérea. De maneira geral, constata-se a lógica de aprofundamento da servitização (CASTELLACCI, 2008; MIOZZO; SOETE, 2001).

\subsection{Estruturas de mercado com grandes alterações: novas categorias de produtos, novos modelos de negócios e novos entrantes}

A oferta mundial de VANT militares está concentrada nos EUA e em Israel, que respondem por mais de $80 \%$ das exportaçóes dessa categoria (SIPRI, 2018), enquanto o mercado de equipamentos recreativos é dominando pelas empresas chinesas. Atualmente, a quase totalidade dos VANTs em operação pode ser classificada como aeronaves remotamente pilotadas (ARP), isto é, aeronaves pilotadas pelo homem que se encontram nos centros de controle em solo. Neste sentido, as inovaçóes mais disruptivas estão relacionadas com as tecnologias de IA e visam o desenvolvimento de VANT cada vez mais autônomos que operem sem a interferência do homem, tanto 
no que se refere ao controle de voo, como na execução de missóes (ROTH, 2019). O desenvolvimento de VANTs completamente autônomos, derivados de modelos experimentais (como o Northrop GrummanX-47B e o Dassault nEUROn) devem avançar e atingir o nível operacional ainda na década de 2020 (DYNDAL; BERNSTEN; REDSE-JOHANSEN, 2017; YENNE, 2017). Os avanços nas tecnologias de rede e da IoT também produzirão impactos disruptivos, ao possibilitar não apenas a operação autônoma dos VANT, mas também a operação conjunta e coordenada entre eles. Esta capacitação de exercer atitudes colaborativas passa a ser essencial para as operaçóes centradas em rede (network centricoperations) e para as operaçóes em enxame (swarm) (MEHTA, 2017). Os avanços nas tecnologias de armazenamento de energia também deverão promover impactos disruptivos ao possibilitar operaçôes de VANT de médio e grande porte com motores elétricos. Neste contexto observa-se que a estrutura de oferta mundial passa por dois movimentos simultâneos. De um lado, um rápido processo de concentração das categorias com tecnologias mais consolidadas. De outro lado, o intenso esforço no desenvolvimento e incorporação de novas tecnologias que deverá manter o elevado dinamismo desse segmento, possibilitando a contínua abertura de janelas de oportunidade para novos entrantes.

\subsection{Criação de um novo segmento: Veículos aéreos urbanos autônomos}

Existe uma elevada probabilidade de que o impacto das inovaçôes disruptivas resultará na criação de um novo e dinâmico segmento, que, no futuro, poderá extrapolar as próprias fronteiras da indústria aeronáutica, o denominado segmento de veículos aéreos urbanos autônomos. Cabe destacar que este é um segmento completamente novo que combina a fabricação de aeronaves com a prestação de serviço de transporte aéreo urbano de uso compartilhado.

Estes novos veículos aéreos utilizarão propulsão elétrica, devendo incorporar as mais avançadas tecnologias de armazenamento de energia. Estas aeronaves serão produzidas em materiais avançados, com a expectativa de elevado uso dos compósitos nanoestruturados. No entanto, as inovaçóes mais disruptivas estão relacionadas com as tecnologias de IA, sensores avançados (IoT) e a segurança em redes de comunicação, pois estão sendo utilizadas para desenvolver o sistema de pilotagem autônomo que otimizem as rotas e permitam que diversos veículos compartilhem o céu, além de operarem com elevado nível de segurança (LORAL, 2017).

A estrutura produtiva deste novo segmento ainda é bastante incipiente, mas atualmente existe um grande número de projetos que estão sendo desenvolvidos em 
paralelo, com elevado grau de convergência tecnológica e de modelo de negócios entre eles. $\mathrm{Na}$ esfera tecnológica, observa-se o desenvolvimento de uma nova categoria de aeronaves multirotores de decolagem e aterrissagem vertical, com propulsão elétrica, denominadas Electrical Vertical Take-Off and Landing Vehicles (eVTOL). Essas aeronaves de dois a quatro assentos deverão ter uma autonomia de voo de cerca de 45 minutos e voar numa velocidade estimada entre 50 e $100 \mathrm{~km} / \mathrm{h}$ (TUCKER, 2018).

Entre os diversos projetos, cinco se destacam. O projeto Uber Elevate, capitaneado pela Uber, empresa de aplicativo na área do transporte privado urbano, também conta com a participação da Embraer, Bell Helicopter, Aurora Flight Sciences (grupo Boeing), Pipistrel, Mooney International Corp, além do apoio dos governos locais de Dallas e Dubai (UBER ELEVATE, 2016; EMBRAER, 2019). Destaca-se ainda o decisivo suporte técnico e financeiro do governo federal dos EUA, através da NASA (GIBBS, 2017). O segundo projeto em destaque é o Vahana, que está sendo desenvolvido pela empresa $\mathrm{A}^{3}$, a subsidiária da Airbus para projetos disruptivos constituída em 2015 no Silicon Valley (EUA). Cabe destacar que em janeiro de 2018, o protótipo do Vahana realizou seu primeiro voo, mas ainda náo tripulado (LOVERING, 2018). Outros dois projetos foram desenvolvidos por start-ups alemãs. A empresa Volocopter é a pioneira mundial deste novo segmento, tendo realizado o primeiro voo tripulado de um eVTOL, no ano de 2016. Essa empresa recebeu um grande aporte de recursos do grupo automobilístico Daimler e recentemente fechou uma parceria com a Intel. O modelo mais recente, o Volocopter $2 \mathrm{X}$, tem capacidade para duas pessoas e, atualmente, uma versão com pilotagem autônoma está sendo testada em Dubai (TUCKER, 2018). Por sua vez, a empresa Lilium, fundada em 2015, vem desenvolvendo um projeto inovador alimentado por 36 pequenos motores a jato de propulsão elétrica, ao invés de rotores. Em 2017 realizou o primeiro voo não tripulado do seu protótipo, que tem previsão para entrar em operação no ano de 2025. Por fim, o projeto mais avançado é o modelo Ehang 116, desenvolvido pela empresa Ehang, uma start-up chinesa criada em 2014. O modelo inicialmente de apenas um lugar, foi apresentado em 2016 e a partir de 2018 iniciou uma ampla série de testes de voo autônomo, muitos dos quais tripulados, além de incluir uma versão de dois lugares, o Ehang, 216. Nos últimos dois anos a empresa entregou 38 aeronaves para fins de teste, treinamento e demonstração e construiu dois centros de comando e controle para gerenciamento de operaçôes em duas cidades (EVTOL.News, 2020).

Observa-se que quatro dos cinco empreendimentos foram iniciados por startups, demonstrando a elevada capacidade das pequenas empresas de base tecnológica 
em avançar nas inovaçóes disruptivas. Por outro lado, há uma tendência destas start-ups serem incorporadas ou estarem associadas aos grandes grupos empresariais em decorrência da crescente necessidade de capital requerido por estes projetos (UTTERBACK, 1996). Esta tendência de consolidação é corroborada pelo fato de que, atualmente, três destes cinco empreendimentos já são comandados ou contam com a decisiva participação de grandes empresas do setor aeronáutico ou automobilístico, além do empreendimento chinês que inicialmente contou com o suporte do poder municipal de Guangzhou e em 2019 abriu capital na Nasdaq Stock Market (EUA).

\section{Resultados e análise}

Observa-se que um amplo conjunto de novas tecnologias complementares e integradas - um cluster de clusters - vem impactando o conjunto da estrutura produtiva em âmbito global, incluindo o objeto deste trabalho, a indústria aeronáutica. Contudo, as modificaçôes proporcionadas por estas inovaçôes não são homogêneas e, além disso, variam de acordo com o segmento da indústria aeronáutica em que estas tecnologias são introduzidas. Para facilitar a análise, foi desenvolvido um quadro síntese (Quadro 2), no qual as inovaçôes abrangidas pelos clusters tecnológicos foram divididas em três categorias, considerando não apenas as mudanças atuais, mas também seu potencial de mudança até 2029: (M) moderado, as inovaçôes devem ser muito restritas e, consequentemente, não trarão mudanças na trajetória tecnológica; (T) transformador, quando uma tecnologia for progressivamente incorporada, promovendo transformaçóes significativas, entretanto, sem resultar numa ruptura da trajetória tecnológica; (D) disruptivo, quando existe a expectativa de que as inovaçóes tecnológicas resultem na ruptura da trajetória tecnológica vigente.

De acordo com o Quadro 2, a maior parte das mudanças proporcionadas pelas novas tecnologias tem caráter transformador e os avanços devem ser incorporados de maneira incremental ao longo dos próximos dez anos. Esta é a situação das tecnologias relacionadas diretamente com as atividades produtivas, no caso a produção inteligente e conectada e a utilização dos materiais avançados. Contudo, observa-se que a introdução de novos materiais está promovendo um impacto disruptivo no segmento de jatos executivos, pois possibilitou que a empresa japonesa Honda conquistasse a liderança em sua categoria de mercado, com o lançamento do HondaJet produzido em compósitos. Apesar disto, a tendência predominante 
na indústria aeronáutica é que os novos materiais sejam introduzidos de forma gradual e passem a ser utilizados de maneira combinada, como já vem sendo feito nos avióes de caça de quinta geração.

QUADRO 2

Indústria aeronáutica: características das novas tecnologias, por segmento (2020-2029)

\begin{tabular}{|l|c|c|c|c|c|c|}
\hline \multicolumn{1}{|c|}{ Segmentos } & \multicolumn{5}{|c|}{ Tecnologias } \\
\hline Segmentos & IA & Rede & IoT & PIC & MA & AE \\
\hline $\begin{array}{l}\text { Aviōes Comerciais } \\
\text { a Jato }\end{array}$ & $\mathrm{T}$ & $\mathrm{T}$ & $\mathrm{T}$ & $\mathrm{T}$ & $\mathrm{T}$ & $\mathrm{M}$ \\
\hline $\begin{array}{l}\text { Aviōes Comerciais } \\
\text { Turboélice }\end{array}$ & $\mathrm{T}$ & $\mathrm{T}$ & $\mathrm{T}$ & $\mathrm{T}$ & $\mathrm{T}$ & $\mathrm{T}$ \\
\hline Jatos Executivos & $\mathrm{D}$ & $\mathrm{T}$ & $\mathrm{T}$ & $\mathrm{T}$ & $\mathrm{D}$ & $\mathrm{M}$ \\
\hline Aviōes Leves & $\mathrm{T}$ & $\mathrm{M}$ & $\mathrm{M}$ & $\mathrm{T}$ & $\mathrm{T}$ & $\mathrm{D}$ \\
\hline Aviōes de Caça & $\mathrm{T}$ & $\mathrm{T}$ & $\mathrm{T}$ & $\mathrm{T}$ & $\mathrm{T}$ & $\mathrm{M}$ \\
\hline $\begin{array}{l}\text { Aviōes de Treina- } \\
\text { mento Militar }\end{array}$ & $\mathrm{D}$ & $\mathrm{T}$ & $\mathrm{T}$ & $\mathrm{T}$ & $\mathrm{T}$ & $\mathrm{M}$ \\
\hline $\begin{array}{l}\text { Aviōes de Transporte } \\
\text { Militar }\end{array}$ & $\mathrm{T}$ & $\mathrm{T}$ & $\mathrm{T}$ & $\mathrm{T}$ & $\mathrm{T}$ & $\mathrm{M}$ \\
\hline Helicópteros & $\mathrm{T}$ & $\mathrm{T}$ & $\mathrm{T}$ & $\mathrm{T}$ & $\mathrm{T}$ & $\mathrm{M}$ \\
\hline VANTs & $\mathrm{D}$ & $\mathrm{D}$ & $\mathrm{D}$ & $\mathrm{T}$ & $\mathrm{T}$ & $\mathrm{D}$ \\
\hline
\end{tabular}

Fonte: Elaboração própria.

Nota: Tecnologias: IA (Inteligência Artificial), Rede, IoT (Internet das Coisas), PIC (Produçâo Inteligente e Conectada), MA (Materiais Avançados) e AE (Armazenamento de Energia).

Conceitos sobre mudanças tecnológicas: M (Moderado), T (Transformador) e D (Disruptivo).

Os avanços tecnológicos relacionados ao armazenamento de energia ainda são muito restritos, mas devem proporcionar impactos disruptivos ao longo dos próximos dez anos, pois irão alterar o sistema de propulsão e, consequentemente, o projeto das aeronaves nos quais forem introduzidos. No entanto, dado o baixo grau de maturidade desta tecnologia, a propulsão elétrica deve ser introduzida e difundida apenas no segmento de aviôes leves, além de ter o seu uso ampliado no segmento de VANT. Também existe a expectativa de que sejam lançados alguns modelos de aeronaves comerciais leves com propulsão híbrida, mas esta tecnologia não deve ter um impacto disruptivo neste segmento ao longo do período analisado, pois deve estar restrita a alguns modelos experimentais. Em razão disso, foi classificada, neste último segmento, como tecnologia com potencial transformador.

As inovaçôes derivadas das TICs (IA, redes e IoT) vêm sendo introduzidas de maneira incremental em praticamente todos os segmentos da indústria aeronáutica. 
A expectativa é de que continuarão a ser gradualmente introduzidas, com potencial transformador em quase todos os segmentos. A exceção deverá fica por conta da IA, cujas mudanças já vêm apresentando um caráter disruptivo em três segmentos: (i) avióes de treinamento militar, por permitir o desenvolvimento de simuladores de alta eficiência e baixos custos; (ii) jatos executivos, ao possibilitar o desenvolvimento de aplicativos que otimizem o uso destas aeronaves; e (iii) VANTs, por viabilizar operaçóes autônomas, conjuntas e coordenadas entre eles.

O impacto dessas novas tecnologias sobre cada segmento da indústria aeronáutica depende não apenas do potencial disruptivo das inovaçóes, mas também da estrutura de mercado preexistente discutida na seção anterior. Com base nestes dois aspectos, foi elaborado o Quadro 3, que apresenta um resumo sobre o impacto das tecnologias da Indústria 4.0 sobre a estrutura de mercado dos diferentes segmentos que compóem a indústria aeronáutica mundial.

Em dois segmentos os impactos das novas tecnologias sobre a estrutura de mercado são muito restritos. O segmento de asas rotativas é um oligopólio global concentrado em poucas empresas, a tecnologia é bastante específica e madura e as mudanças tecnológicas devem ter um caráter incremental. Outro segmento é o de avióes de caça, cuja expectativa é que ocorram, no máximo, algumas mudanças de posição entre as empresas já estabelecidas.

Contudo, em quatro, dos nove segmentos da indústria aeronáutica, a expectativa é que o impacto das novas tecnologias resulte em modificaçóes na estrutura de mercado relacionadas com a entrada de novos concorrentes. A quase totalidade das mudanças tecnológicas que recaem sobre estes quatro segmentos possui um caráter transformador. Ainda assim, a introdução de novos projetos que incorporem e sintetizem tais mudanças abrem a possibilidade para empresas entrantes que venham acompanhar ou mesmo suplantar as já estabelecidas. A diferença de impacto entre esses quatro segmentos se refere ao nível de concentração da estrutura de mercado previamente existente. No segmento de aviôes comerciais a jato, as empresas do duopólio - Boeing e Airbus - buscaram adotar estratégias defensivas visando reforçar o poder de mercado frente às entrantes, particularmente através da extensão deste duopólio para a categoria inferior. No entanto, apenas a empresa europeia logrou êxito, enquanto a empresa estadunidense vem enfrentando uma grave crise técnica e financeira. Por consequência há uma manutenção dos duopólios, Airbus-Boeing nas categorias superiores, e Airbus-Embraer, na categoria de até 150 assentos. Neste contexto, as empresas entrantes devem ocupar apenas uma parcela marginal ao longo da década. 


\section{QUADRO 3}

Estrutura de mercado da indústria aeronáutica: características, empresas líderes, impactos das novas tecnologias e tipologia proposta (2020-2029)

\begin{tabular}{|c|c|c|c|c|c|}
\hline \multirow{2}{*}{ Subsegmentos } & \multirow{2}{*}{$\begin{array}{c}\text { Estruturas } \\
\text { de Mercado } \\
\text { (Características) }\end{array}$} & \multirow{2}{*}{$\begin{array}{l}\text { Empresas } \\
\text { Líderes }\end{array}$} & \multicolumn{2}{|c|}{$\begin{array}{l}\text { Impacto das novas tecnologias sobre } \\
\text { a estrutura de mercado }\end{array}$} & \multirow{2}{*}{$\begin{array}{l}\text { Tipologia } \\
\text { Proposta }\end{array}$} \\
\hline & & & $\begin{array}{l}\text { Resultados } \\
\text { atuais }\end{array}$ & $\begin{array}{l}\text { Resultados até } \\
2027\end{array}$ & \\
\hline $\begin{array}{c}\text { Asas } \\
\text { Rotativas }\end{array}$ & $\begin{array}{l}\text { Alta } \\
\text { concentração } \\
\text { (tecnologia } \\
\text { específica) }\end{array}$ & $\begin{array}{l}\text { Airbus, } \\
\text { Sikorsky, } \\
\text { Leonardo } \\
\text { e Russian } \\
\text { Helicopter }\end{array}$ & \multicolumn{2}{|c|}{ Manunteção do oligopólio existente } & \multirow{2}{*}{$\begin{array}{c}\text { Sem mudanças: } \\
\text { Manutençáo } \\
\text { da estrutura } \\
\text { existente }\end{array}$} \\
\hline $\begin{array}{l}\text { Avióes de } \\
\text { caça }\end{array}$ & $\begin{array}{l}\text { Alta } \\
\text { concentração } \\
\text { (fronteira } \\
\text { tecnológica) }\end{array}$ & $\begin{array}{l}\text { Lockheed } \\
\text { Martin }\end{array}$ & $\begin{array}{l}\text { Avanço da AVIC } \\
\text { (China) e da } \\
\text { Rússia (UAC) } \\
\text { e atraso dos } \\
\text { europeus }\end{array}$ & $\begin{array}{l}\text { Mudanças de } \\
\text { posição dentro } \\
\text { do oligopólio }\end{array}$ & \\
\hline $\begin{array}{c}\text { Jatos } \\
\text { Comerciais }\end{array}$ & Duopólio & $\begin{array}{l}\text { Boeing e } \\
\text { Airbus }\end{array}$ & $\begin{array}{l}\text { Entrada da AVIC } \\
\text { (China) e UAC } \\
\text { (Rússia) }\end{array}$ & $\begin{array}{l}\text { Fim do dopólio, } \\
\text { mas entrantes } \\
\text { ocupam posição } \\
\text { marginal }\end{array}$ & \multirow{4}{*}{$\begin{array}{c}\text { Pequenas } \\
\text { mudanças: } \\
\text { Novos entrantes }\end{array}$} \\
\hline $\begin{array}{l}\text { Comerciais } \\
\text { Turboélices }\end{array}$ & Duopólio & $\begin{array}{l}\text { ATR e } \\
\text { Viking Air }\end{array}$ & $\begin{array}{l}\text { Entrada da AVIC } \\
\text { (China) }\end{array}$ & $\begin{array}{l}\text { Fim do dopólio, } \\
\text { com entrantes } \\
\text { ocupando parcela } \\
\text { relevante }\end{array}$ & \\
\hline $\begin{array}{l}\text { Transporte } \\
\text { Militar }\end{array}$ & $\begin{array}{l}\text { Oligopólio } \\
\text { concentrado }\end{array}$ & $\begin{array}{l}\text { Airbus, } \\
\text { UAC e } \\
\text { Lockheed } \\
\text { Martin }\end{array}$ & $\begin{array}{l}\text { Entrada da } \\
\text { Embraer (Brasil) }\end{array}$ & $\begin{array}{l}\text { Consolidação de } \\
\text { um oligopólio } \\
\text { mais abrangente }\end{array}$ & \\
\hline Aviónes leves & $\begin{array}{l}\text { Pulverizada em } \\
\text { médias empresas }\end{array}$ & $\begin{array}{l}\text { Cirrus, } \\
\text { Grob e } \\
\text { Cessna }\end{array}$ & $\begin{array}{l}\text { Avanço das } \\
\text { empresas dos } \\
\text { países emergentes }\end{array}$ & $\begin{array}{l}\text { Estrutura } \\
\text { dinâmica e } \\
\text { pulverizada }\end{array}$ & \\
\hline $\begin{array}{c}\text { Jatos } \\
\text { executivos }\end{array}$ & $\begin{array}{l}\text { Oligopólio } \\
\text { concentrado }\end{array}$ & $\begin{array}{l}\text { Bombardier, } \\
\text { Gulfstream } \\
\text { e Dassault }\end{array}$ & $\begin{array}{l}\text { Entrada da Honda } \\
\text { (Japáo/EUA) }\end{array}$ & $\begin{array}{l}\text { Venda de } \\
\text { serviços de } \\
\text { transporte } \\
\text { executivos }\end{array}$ & \multirow{2}{*}{$\begin{array}{l}\text { Mudanças } \\
\text { intermediárias: } \\
\text { Novos modelos } \\
\text { de negócio }\end{array}$} \\
\hline $\begin{array}{l}\text { Treinamento } \\
\text { Militar }\end{array}$ & $\begin{array}{l}\text { Alianças } \\
\text { estratégicas }\end{array}$ & $\begin{array}{l}\text { UAC, } \\
\text { Leonardo, } \\
\text { KAI }\end{array}$ & $\begin{array}{l}\text { Fortalecimento das } \\
\text { alianças }\end{array}$ & $\begin{array}{l}\text { Venda de } \\
\text { serviços de } \\
\text { treinamento } \\
\text { militar }\end{array}$ & \\
\hline VANTs & $\begin{array}{l}\text { Estrutura pouco } \\
\text { consolidada }\end{array}$ & $\begin{array}{l}\text { General } \\
\text { Atomics e } \\
\text { DJI }\end{array}$ & $\begin{array}{l}\text { Consolidação } \\
\text { e janelas de } \\
\text { oportunidade }\end{array}$ & $\begin{array}{l}\text { Novas } \\
\text { empresas }\end{array}$ & $\begin{array}{l}\text { Grandes } \\
\text { mudanças: } \\
\text { Novas } \\
\text { categorias de } \\
\text { produtos }\end{array}$ \\
\hline EVTOL & $\begin{array}{l}\text { Estrutura } \\
\text { inexistente }\end{array}$ & $\begin{array}{l}\text { Consórcio } \\
\text { Uber, A3, } \\
\text { Volocopter, } \\
\text { Lilium e } \\
\text { Ehang }\end{array}$ & $\begin{array}{l}\text { Empresas } \\
\text { nascentes }\end{array}$ & $\begin{array}{l}\text { Consolidação do } \\
\text { novo segmento }\end{array}$ & Novo segmento \\
\hline
\end{tabular}

Fonte: Elaboração própria. 
Nos segmentos de avióes comerciais turboélices e de avióes de transporte militares, em que há uma menor concentração de mercado e baixo dinamismo tecnológico, a expectativa é que as empresas entrantes ocupem uma parcela significativa destes mercados. Por fim, no segmento de avióes leves, cuja estrutura de mercado é pulverizada, a expectativa é que exista um considerável número de entrantes, em grande parte decorrente da introdução dos aviôes elétricos leves.

Em dois segmentos, o impacto das novas tecnologias, mais especificamente da IA, deverá ser mais abrangente e propiciar o surgimento de novos modelos de negócios, centrados não mais na venda de aeronaves, mas de serviços, a denominada servitizaçáo. No segmento de jatos executivos, a venda de serviços de transporte aéreo de uso privado ou compartilhado, através de aplicativos. No segmento de avióes de treinamento militar, a venda de serviços de formação de pilotos para as forças aéreas, sem que estas necessitem adquirir as aeronaves e simuladores.

No segmento de VANT, observou-se que a maioria das mudanças tecnológicas apresenta caráter disruptivo e provavelmente conduzirão ao desenvolvimento de novas categorias de produtos e novos modelos de negócios. Como resultado desse elevado dinamismo, a estrutura de mercado continuará a apresentar dois movimentos paralelos, mas em sentidos contrários. De um lado, a concentração nas categorias de produtos já estabelecidas e, de outro, a criação de novas categorias, abrindo janelas de oportunidades para novas empresas e, até mesmo, para novos modelos de negócios.

Constata-se, por fim, que existe uma elevada probabilidade deste conjunto de novas tecnologias resultar na criação de um novo segmento que estará centrado na oferta de serviços de transporte aéreo urbano de uso compartilhado, com o uso de veículos de pouso e decolagem vertical, propulsão elétrica e pilotagem autônoma (eVTOL). Apesar do atual estágio embrionário, este novo segmento poderá se consolidar, em breve, como um novo e promissor segmento de alta tecnologia que combine a fabricação dos veículos aéreos inovadores com a prestação de serviços de transporte aéreo urbano.

\section{Considerações finais}

O amplo conjunto de novas tecnologias - direta ou indiretamente associadas à Indústria 4.0 - está tendo um impacto significativo sobre a indústria aeronáutica e alterará, de alguma maneira, a forma como é conhecida. No entanto, este impacto não é homogêneo, apresentando grandes diferenças entre os segmentos de mercado que a compóem. Estas diferenças decorrem não apenas das características das novas 
tecnologias que impactam um determinado segmento, mas também da estrutura de mercado preexisteente em cada um deles. Neste sentido, é coerente estabelecer que, quanto mais consolidado for um segmento, menor tende a ser o impacto das mudanças tecnológicas sobre a estrutura de mercado, ao menos, no curto prazo. A luz da literatura é possível considerar que esta diversidade de resultados decorre da cumulatividade de conhecimentos e competências no interior da indústria aeronáutica, combinada com a expectativa de evolução das novas tecnologias. Por fim, este trabalho identificou que o conjunto de tecnologias disruptivas também tem a capacidade para conformação de um novo segmento dentro da indústria aeronáutica, evidenciando o potencial criativo das novas tecnologias, como apresentado por Schumpeter.

\section{Referências}

ABERNATHY, W.; UTTERBACK, J. Patterns of industrial innovation. Technology Review, Cambridge, v. 80, n. 7, p. 40-47, 1978.

ALLISON, G. Airbus hoping to combine British Tempest jet project with Franco-German effort. UK Defence Journal, Nov. 26, 2019. Disponível em: https://ukdefencejournal.org. uk/airbus-hoping-to-combine-british-tempest-jet-project-with-franco-german-effort/. Acesso em: jul. 2020.

AWIN - AVIATION WEEW INTELLIGENCE NETWORK. Database, 2018. Disponível em: http://aviationweek.com/aviation-week-intelligence-network. Acesso em: maio 2019.

BAINES, T.; ZIAEE BIGDELI, A.; BUSTINZA, O.; SHI, V.; BALDWIN, J.; RIDGWAY, K. Servitization: revisiting the state-of-the-art and research priorities. International Journal of Operations \& Production Management, v. 37 n. 2, p. 256-278, 2017.

BORDEAUX-REGO, A.C. Cluster Tecnológico: Internet das Coisas. Documento Interno de Trabalho, Projeto Indústria 2027. Rio de Janeiro, IE-UFRJ; Campinas, IE-Unicamp, 2017.

CARVALHO, A.J.F. Cluster Tecnológico: Materiais Avançados. Documento Interno de Trabalho, Projeto Indústria 2027. Rio de Janeiro, IE-UFRJ; Campinas: IE-Unicamp, 2017.

CASTELLACCI, F. Technological paradigms, regimes and trajectories: Manufacturing and service industries in a new taxonomy of sectoral patterns of innovation. Research Policy, v. 37, n. 6, p. 978-994, 2008.

COUTINHO, L.G. A terceira revolução industrial e tecnológica. As grandes tendências das mudanças. Economia e Sociedade, Campinas, v. 1, n. 1, p. 69-87, ago. 1992. 
COUTINHO, L.G.; FERRAZ, J.C.; KUPFER, D.; PENNA, C. (coord.). Mapa de Clusters Tecnológicos e Tecnologias Relevantes para a Competitividade de Sistemas Produtivos. Documento Interno de Trabalho. Rio de Janeiro, IE-UFRJ; Campinas, IE-Unicamp, 2018.

CRABBE, J. Cutting edge it at Boeing: Transforming commercial aviation using WS02. WSO2, 7 Oct. 2013. Disponível em: https://wso2.com/library/wso2con2013-usa/keynote-cutting-edge-it-at-boeing-transforming-commercial-aviation-using-wso2/. Acesso em: ago.2018.

DOSI, G. Technological paradigms and technological trajectories: a suggested interpretation of the determinants and directions of technical change. Research Policy, v. 11, n. 3, June 1982.

DOSI, G. Sources, procedures and microeconomic effects of innovation. Journal of Economic Literature, v. 36, n. 3, p. 1120-1171, Sept. 1988.

DRUMOND, C. De Asas Quebradas. Carta Capital, 6 maio 2020.

DYNDAL, G.L.; BERNSTEN, T.A.; REDSE-JOHANSEN, S. Autonomous military drones: no longer science fiction. NATO Review, July 28, 2017. Disponível em: https://www.nato. $\mathrm{int} /$ docu/review/articles/2017/07/28/autonomous-military-drones-no-longer-science-fiction/ index.html. Acesso em: jul. 2020.

EMBRAER. Flight Plan 2030. Embraer X, May 2019. Disponível em: https://daflwcl3bnxyt. cloudfront.net/m/f58fb8ea648aeb9/original/EmbraerX-White-Paper-Flight-Plan2030.pdf. Acesso em: jul. 2020.

ERBOZ, G. How To Define Industry 4.0: Main Pillars Of Industry 4.0. Nitra, Slovak University of Agriculture, Nov. 1, 2017. Disponível em: https://www.researchgate.net/ publication/326557388. Acessado em: jul. 2020.

EVTOL.NEWS. The Electric VTOL News - eVTOL Aircraft Directory. Disponível em: https://evtol.news/aircraft. Acesso em: jul. 2020

FERREIRA, M.J.B. Dinâmica da inovaçâo e mudanças estruturais: um estudo de caso da indústria aeronáutica mundial e a inserção brasileira. Tese (Doutorado) - Instituto de Economia, Universidade de Campinas, Campinas, 2009.

FERREIRA, M.J.B. Estudo de sistema produtivo aeroespacial e defesa. Brasília, IEL/NC, 100 p. il., 2018. (Projeto Indústria 2027: riscos e oportunidades para o Brasil diante de inovaçóes disruptivas).

FREEMAN, C.; SOETE, L. A economia da inovação industrial. Campinas: Editora da Unicamp, 2008 [1997].

GARCIA, M. Airbus Buys Bombardier Out Of Commercial Aviation For \$591 Million. Forbes, Feb. 13, 2020. Disponível em: https://www.forbes.com/sites/marisagarcia/2020/02/13/ 
airbus-buys-bombardier-out-of-commercial-aviation-for-591-million/\#1631d9e51783. Acesso em: jul. 2020.

GATES, D. Costs mount as Mitsubishi SpaceJet is delayed again. The Seattle Times, Feb. 6, 2020. Disponível em: https://www.seattletimes.com/business/boeing-aerospace/costs-mountas-mitsubishi-spacejet-is-delayed-again/. Acesso em: jul. 2020.

GIBBS, S. Uber signs contract with Nasa to develop flying taxi software. The Guardian, Nov. 8, 2017. Disponível em: https://www.theguardian.com/technology/2017/nov/08/uber-signs-contract-nasa-develop-flying-taxi-software. Acesso em: set. 2018.

GINADER, K. Lead-In Fighter Training Considerations for 5th Generation Aircraft, 2013. Disponível em: http://www.etcusa.com/etc-newsletter/lead-in-fighter-training-considerations-for-5th-generation-aircraft/. Acesso em: ago. 2018.

GOH, B. China, Russia set up wide-body jet firm in new challenge to Boeing, Airbus. Reuters, May 22, 2017. Disponível em: https://www.reuters.com/article/us-china-comac-russia-idUSKBN18I0KZ. Acesso em: set. 2018.

HAYNES, B. Embraer pode produzir turboélice para competir com ATR e Bombardier. Época Negócios, 15 set. 2017. Disponível em https:/epocanegocios.globo.com/Empresa/ noticia/2017/09/epoca-negocios-embraer-pode-produzir-turboelice-paracompetir-com-atr-e-bombardier.html. Acesso em: jul. 2018.

HEMMERDINGER, J. Mitsubishi closes CRJ acquisition despite SpaceJet uncertainty. Flight Global, June 1, 2020. Disponível em: https://www.flightglobal.com/airframers/mitsubishi-closes-crj-acquisition-despite-spacejet-uncertainty/138629.article. Acesso em: jul. 2020.

ICAO. Effects of Novel Coronavirus (COVID-19) on Civil Aviation: Economic Impact Analysis. ICAO, Montreal, July 13, 2020. Disponível em: https://www.icao.int/sustainability/Documents/COVID-19/ICAO_Coronavirus_Econ_Impact.pdf. Acesso em: jul. 2020.

JOSEPHS, L. Brazil's Embraer says Boeing 'wrongfully terminated' deal for $\$ 4$ billion tie-up. CNBC, Apr. 25, 2020. Disponível em: https://www.cnbc.com/2020/04/25/boeing-terminates-joint-venture-agreement-with-brazils-embraer.html. Acesso em: jul. 2020.

JUDSON, J. US Army plans to field a future long-range assault helicopter by 2030. DefenseNews, Apr. 4, 2020. Disponível em: https://www.defensenews.com/land/2019/04/04/ us-army-plans-to-field-a-future-long-range-assault-helicopter-by-2030/. Acesso em: jul. 2020.

KLINE, S.J.; ROSENBERG, N. An overview of innovation. In: LANDAU, R.; ROSENBERG, N. (ed.). The positive sum of strategy: harnessing technology for economic growth. Washington, DC: National Academy Press, 1986. p. 275-305. 
KLOTZEL, E. A construção do avião do future. AERO Magazine, 16 maio 2015. Disponível em: http://aeromagazine.uol.com.br/artigo/construcao-do-aviao-do-futuro_2112.html. Acesso em: set. 2018.

KPMG. After the shock: Perspectivas para o Setor Aeroespacial e de Defesa. KPMG, July 2020. Disponível em: https://assets.kpmg/content/dam/kpmg/br/pdf/2020/07/br-after-the-shock-aerospace-defense.pdf. Acesso em: jul. 2020.

LEBOULANGER, A.; KIMLA, D. Military Training \& Simulation Market Spreads its Wings. Frost\&Sullivan, 2013.

LORAL, C.A. Cluster Tecnológico: Tecnologias de Redes. Documento Interno de Trabalho, Projeto Indústria 2027. Rio de Janeiro, IE-UFRJ; Campinas, IE-Unicamp, 2017.

LOVERING, Z. Vahana’s First Flight a Success. Vahana, Feb. 1, 2018. Disponível em: https://vahana.aero/vahanas-first-flight-a-success-ade26d26ba02. Acesso em: ago.2018.

LUNDVALL, B.Å. National innovation systems: analytical concepts and development tools. Industry \& Innovation, v 14, n 1, p. 95-119, Feb. 2007.

MALERBA, F. Sectoral systems of innovation and production. Research Policy, v. 31, n. 2, p. 247-264, Feb. 2002.

MANTEGHI, A; MANTEGHI, M; ASLANJ, A.; MOHAGHAR, A. Catch-up Process in Aircraft Industry: A Model Based on Experiences of Six Latecomer Countries. International Journal of Sociotechnology and Knowledge Development, v. 10, n. 1, p. 37-56, 2018.

MCKINSEY \& COMPANY. Industry 4.0 after the initial hype: Where manufactures are finding value and how they can best capture it. McKinsey Digital, 2016.

MEHTA, A. Pentagon Launches 103 Unit Drone Swarm. DefenseNews, v.10, Jan. 2017. Disponível em: https://www.defensenews.com/air/2017/01/10/pentagon-launches-103-unit-drone-swarm/. Acesso em: set. 2018.

MEIER, R. Irkut MC-21 passenger aircraft due to enter service in late 2021. Airway, June 30, 2020. Disponível em: https:/www.airway1.com/irkut-mc-21-passenger-aircraft-due-to-enter-service-in-late-2021/. Acesso em: jul. 2020.

MILES, I. Innovation in services. In: FAGERBERG, J.; MOWERY, D.; NELSON, R. (ed.). The Oxford Handbook of Innovation. Oxford: Oxford University Press, 2006. p. 433-458.

MIOZZO, M.; SOETE, L. Internationalization of services: a technological perspective. Technological Forecasting and Social Change. v. 67, p.159-185, 2001.

MOWERY, D; ROSENBERG, N. Trajetórias da Inovação: A mudança tecnológica nos Estados Unidos da América no século XX. Campinas: Editora da Unicamp, 2005. 
NAVEIRO, R. M. Cluster Tecnológico: Produção Inteligente e Conectada. Documento Interno de Trabalho, Projeto Indústria 2027. Rio de Janeiro, IE-UFRJ; Campinas, IE-Unicamp, 2017. NAYAK, N.V. Composite Materials in Aerospace Applications. International Journal of Scientific and Research Publications, v. 4, n. 9, Sept. 2014.

NELSON, R.R. Co-evolution of industry structure, technology and supporting institutions, and the making of comparative advantage. International Journal of the Economics of Business, v. 2, n. 2, p. 171-184, 1995.

NELSON, R.R.; WINTER, S.G. In search of a useful theory of innovation. Research Policy, v. 6, n. 1, p. 36-76, Jan. 1977.

NELSON, R.R.; WINTER, S.G. Uma teoria evolucionária da mudança econômica. Campinas: Editora da Unicamp, 2006 [1982].

PENROSE, E. A teoria do crescimento da firma. Campinas: Editora da Unicamp, 2006 [1959].

PEREZ, C. Technological revolutions and techno-economic paradigms. Cambridge Journal of Economics, v. 34, p. 185-202, 2010.

PRADO, E. Cluster Tecnológico: Inteligência Artificial. Documento Interno de Trabalho, Projeto Indústria 2027. Rio de Janeiro, IE-UFRJ; Campinas, IE-Unicamp, 2017.

QIU, S.; HEPHER, T. China's bid to challenge Boeing and Airbus falters. Reuters, Jan. 9, 2020. Disponível em: https://www.reuters.com/article/us-china-aviation-comac-insight/ chinas-bid-to-challenge-boeing-and-airbus-falters-idUSKBN1Z905N. Acesso em: jul. 2020.

RIBEIRO, G. HondaJet é a nova tendência mundial na aviação executiva. AviaçãoJor, 5 out. 2017. Disponível em: http://aviacao.jor.br/aviacao-geral/hondajet-tendencia-aviacao-executiva/. Acessado em: jul. 2018.

ROSENBERG, N. Por dentro da caixa-preta: tecnologia e economia. Campinas, Editora da Unicamp, 2006 [1982].

ROTH, M. AI in Military Drones and UAVs - Current Applications. Emerj, Nov. 29, 2019. Disponível em: https://emerj.com/ai-sector-overviews/ai-drones-and-uavs-in-the-military-current-applications/. Acesso em: jul. 2020.

SCHUMPETER, J.A. Capitalismo, socialismo e democracia. Rio de Janeiro, Zahar, 1984 [1942].

SCHUMPETER, J.A. Teoria do desenvolvimento econômico. São Paulo, Nova Cultural, 1997 [1934].

SCHWAB, K. The fourth industrial revolution. New York, Crown Business, 2016. 
SIPRI - STOCKHOLM INTERNATIONAL PEACE RESEARCH INSTITUTE. Top 100 arms-producing and military services companies. 2018. Disponível em: https://www.sipri. org/databases. Acesso em: nov. 2018.

THOMSON, R. The number of electrically propelled aircraft developments grew by $-30 \%$ in 2019. Roland Berger, Jan. 15, 2020. Disponível em: https://www.rolandberger.com/en/ Point-of-View/Electric-propulsion-is-finally-on-the-map.html. Acesso em: jul. 2020.

TORRESI, R.M. Cluster Tecnológico: Armazenamento de Energia. Documento Interno de Trabalho, Projeto Indústria 2027. Rio de Janeiro, IE-UFRJ; Campinas, IE-Unicamp, 2017.

TUCKER, I. Air taxis: we have lift-off... The Guardian, Mar. 4, 2018. Disponível em: https://www.theguardian.com/technology/2018/mar/04/air-taxis-we-have-lift-off-airbus-vahana-ehang-volocopter-uber-elevate-lilium. Acesso em: ago. 2018.

UBER ELEVATE. Fast-Forwarding to a Future of On-Demand Urban Air Transportation. Uber Elevate, Oct. 27, 2016. Disponível em: https://www.uber.com/elevate.pdf. Acesso em: dez. 2017.

UBIRATAN. E. O futuro da aviação leve. AERO Magazine, 2 out. 2014. Disponível em: http://aeromagazine.uol.com.br/artigo/o-futuro-da-aviacao-leve_1755.html. Acesso em: dez. 2017.

UTTERBACK, J.M. Dominando a Dinâmica da Inovação. Rio de Janeiro, Qualitymark Editora, 1996.

WEBER, A. Assembly Automation Takes Off in Aerospace Industry. Assembly Magazine, Feb. 4, 2015. Disponível em: https://www.assemblymag.com/articles/92790-assembly-automation-takes-off-in-aerospace-industry. Acesso em: ago. 2018.

WILSON, C. Network Centric Operations: Background and Oversight Issues for Congress. CRS Report for Congress, Mar. 15, 2007. Disponível em: http://www.dtic.mil/dtic/tr/ fulltext/u2/a466624.pdf. Acesso em: ago. 2018.

YENNE, B. Drone Strike!: UCAVs and Unmanned Aerial Warfare in the 21st Century. Forest Lake, Speciality Press, 2017. 


\section{Contribuiçáo dos autores:}

A. Fundamentação teórico-conceitual e problematização: Celso Pereira Neris Jr e Marcos José Barbieri Ferreira

B. Pesquisa de dados e análise estatística: Marcos José Barbieri Ferreira

C. Elaboraçáo de figuras e tabelas: Marcos José Barbieri Ferreira

D. Elaboração e redação do texto: Marcos José Barbieri Ferreira e Celso Pereira Neris Jr

E. Seleção das referências bibliográficas: Marcos José Barbieri Ferreira e Celso Pereira Neris Jr

Conflito de Interesse: os autores declaram que não há conflito de interesses.

Financiamento: Este trabalho se baseia no estudo desenvolvido no âmbito do projeto "I2027 - Risco e oportunidades para o Brasil diante de inovaçóes disruptivas" que teve suporte financeiro do Instituto Euvaldo Lodi (IEL) da Confederação Nacional das Indústrias (CNI).

Este é um artigo publicado em acesso aberto (Open Access) sob a licença Creative Commons Attribution CCBY, que permite uso, distribuição e reprodução em qualquer meio, sem restrições desde que o trabalho original seja corretamente citado. 